El copo y la avalancha. Los estudios sobre Prilidiano Pueyrredón

Lucas Andrés Masán

Boletín de Arte (N. ${ }^{\circ}$ 20), e019, septiembre 2020, ISSN 2314-2502

https://doi.org/10.24215/23142502e019

http://papelcosido.fba.unlp.edu.ar/ojs/index.php/boa

Facultad de Artes. Universidad Nacional de La Plata

La Plata. Buenos Aires. Argentina

\title{
EL COPO Y LA AVALANCHA
}

\section{LOS ESTUDIOS SOBRE PRILIDIANO PUEYRREDÓN}

\section{THE FLAKE AND THE AVALANCHE}

\section{THE STUDIES ABOUT PRILIDIANO PUEYRREDÓN}

\author{
Lucas Andrés Masán / l.andres.m@outlook.com \\ Consejo Nacional de Investigaciones Científicas y Técnicas (CONICET). Centro Interdisciplinario \\ de Estudios Políticos, Sociales y Jurídicos. Universidad del Centro de la Provincia de Buenos \\ Aires. Argentina
}

Recibido: $7 / 3 / 2020$

Aceptado: $26 / 6 / 2020$

\section{RESUMEN}

El siguiente estado de la cuestión se inscribe como parte de una investigación doctoral en curso en la cual abordamos las formas que asumió la sensibilidad visual en el Buenos Aires de 1860 a través de las pinturas de temática rural de Prilidiano Pueyrredón. Por tal motivo, aquí presentamos el rastreo de la literatura referida a sus trabajos pictóricos y la dividimos en dos partes según sus formas de abordaje: los estudios clásicos y los enfoques más recientes.

\section{PALABRAS CLAVE}

Prilidiano Pueyrredón; arte; pintura; historia; nación

\section{ABSTRACT}

The following state of affairs is inscribed as part of an ongoing doctoral research in which we address the forms that visual sensitivity assumed in Buenos Aires in 1860 through the rural paintings of Prilidiano Pueyrredón. For this reason we present here the tracing of the literature referring to his pictorial works and we divide it into two parts according to his approaches: the classic studies and the most recent approaches.

\section{KEYWORDS}

Prilidiano Pueyrredón; art; painting; history; nation 
Prilidiano Pueyrredón (1823-1870) fue uno de los pintores argentinos más destacados del siglo XIX. Creció en Buenos Aires en una familia que gozaba de buena reputación tanto por su posición económica como por el prestigio que rodeaba la figura de su padre, el ex director supremo Juan Martín de Pueyrredón. La familia se trasladó por motivos políticos a Francia en 1835, lo cual hizo que la formación de Prilidiano transcurriese en la École Polytechnique parisina hasta 1850. Con su regreso a Buenos Aires a mediados del siglo XIX, aquel recorrido le permitió posicionarse como un referente cultural destacado, desempeñándose como pintor, ingeniero, arquitecto y urbanista. En el plano social mantuvo vínculos con los sectores dirigentes y cultivó lazos amicales y espacios de sociabilidad notables, desde su relación con figuras, como Domingo Faustino Sarmiento, Miguel de Azcuénaga, Cayetano María Cazón, José Roque Pérez, Vicente Quesada o Juan María Gutiérrez, hasta su participación en sitios como el Concejo Municipal, el almacén Fusoni, la Sociedad Rural o el Círculo Literario. Sus aportes en aquel Buenos Aires fueron heterogéneos, ejecutó numerosas obras en el espacio público mientras que en el plano estrictamente pictórico realizó retratos, paisajes, desnudos y escenas de costumbres tanto urbanas como rurales.

Su figura fue considerada medio siglo después de su fallecimiento, cuando en la década de 1930 su nombre fue inscripto en el universo artístico argentino, emergencia cuyos motivos contienen dos dimensiones entrelazadas. Nos referimos a la revisión del pasado en un contexto nacionalista y a los avatares de su obra, siendo el más significativo el traslado del retrato al óleo de Manuelita de Rosas (1851) del Museo Histórico Nacional (MHN) al Museo Nacional de Bellas Artes (MNBA) en 1933. ${ }^{1}$ Ello motivó la inclusión del pintor en la obra de Eduardo Schiaffino de aquel año y llevó a José León Pagano a condenar como un caso de "ceguera" el no haber reparado hasta entonces en la importancia de su figura (Pagano, 1937). Veamos los trabajos que desde entonces han calibrado su lente sobre Pueyrredón y su pintura.

\section{ABORDAJES CLÁSICOS}

En la década de 1930 se asistió a la irrupción de Pueyrredón en la escena historiográfica con la publicación de un artículo de José León Pagano en el diario La Nación (6 de noviembre de 1932) en el cual señaló la importancia de valorizar las pinturas de Pueyrredón como parte esencial del ser nacional. Un año después, el semanario Caras y Caretas dio cuenta de una exposición de las piezas de aquel "gentil y culto caballero de noble alcurnia" en la Sala Amigos del Arte (Gutiérrez, 1933, p. 125). En términos bibliográficos, los primeros estudios sistemáticos corresponden a dos clásicos de la historiografía del arte nacional como Schiaffino y Pagano. El primero sostuvo una idea que marcaría el pulso de enfoques ulteriores, al considerar las obras como producto de una necesidad intrínseca del espíritu del pintor, como un modo "para dar satisfacción a su temperamento" (Schiaffino, 1933, p. 125), y al colocar al artista como un demiurgo que "salva del olvido la figura legendaria del gaucho argentino" (Schiaffino, 1933, p. 152). El segundo, en análoga tesitura, propuso desarrollar un "salvataje" mediante lo que consideraba la «vindicación» de una figura que "injustamente» había "caído en el olvido" (Pagano, 1937, p. 191).

El contexto político y social de entonces nos permite comprender la súbita irrupción del pintor desde varias aristas. En primer lugar, como una revisión del pasado en pos de las raíces de "lo nacional» bajo una atmósfera de extensión de posicionamientos nacionalistas que «involucraron a gran parte del mundo cultural argentino" (Cataruzza, 2009, p. 148), en la cual se intensificó "el esfuerzo estatal por definir los atributos de esos símbolos que había comenzado en el siglo XIX» (Cataruzza, 1999, p. 432). En esta trama adquirió relieve

1 El MNBA poseía el estudio de este retrato que había sido donado por José Guerrico en 1896. Lo curioso del caso es que el óleo definitivo fue reclamado por el MNBA en 1933 y el MHN cedió la pieza aquel año, encargando una copia al artista Rafael del Villar. Actualmente es posible observar ambas versiones —la original y su duplicado- en estas instituciones (Navarro, 2016; Cabra y otros, 2017). 
el "rescate» de figuras "olvidadas" que, como Pueyrredón, habrían contribuido al "espíritu nacional». Mediante estos rescates la importancia histórica del artista no hizo sino aumentar, al punto de observarse una explosión en la década de 1940, fenómeno que respondió a varias causas vinculadas. Por un lado, la creación de la Escuela Nacional de Bellas Artes el 18 de septiembre de 1940, ${ }^{2}$ a la cual se le otorgó precisamente el nombre de Prilidiano Pueyrredón. Por otro, el impulso dado a las artes con publicaciones, becas y subsidios estimulados por la recientemente fundada Academia Nacional de Bellas Artes (ANBA), lo cual nos provee información respecto al estatus de lo artístico como parte del desarrollo nacional. Finalmente, se asistió a una atmósfera de revalidación y de resignificación de la figura del gaucho con la promoción de fiestas, celebraciones y procesiones, entre las cuales se destacaron no solo la instauración del Día de la Tradición en 1939, sino también la primera procesión a la Iglesia de Luján en 1945 o la erección del primer monumento al gaucho en 1947-1948 (Casas, 2013, 2016). En este contexto es posible considerar la vindicación del artista —y especialmente de su pintura rural - como parte de un entramado que comprendió otros dispositivos tendientes a estimular el sentimiento patriótico. Así, tanto la fundación de la Escuela Prilidiano Pueyrredón como el accionar de la ANBA nos muestran un influjo dado al arte desde el Estado, en sintonía con un contexto nacionalista en el cual se revalorizaba lo nacional y se visualizaban estos aportes como parte de un proyecto tendiente a rescatar el pasado y resituar el presente con miras a cimentar un futuro. En esta atmósfera verán la luz tres trabajos de peso en la literatura sobre Pueyrredón, que fortalecen la trayectoria previamente trazada. Nos referimos a las labores de Jorge Romero Brest, Arminda D’Onofrio y José León Pagano.

El primero propuso una mirada más artística que histórica, subrayando la "actitud estética» de Pueyrredón expresada en la variedad de géneros que cultivó y destacando la "emoción metafísica" que caracterizaban a sus pinturas rurales (Romero Brest, 1942, p. 10). Por su parte, D’Onofrio (1944) realizó un estudio exhaustivo del artista en vínculo con su época en el marco de su tesis doctoral en Literatura, enfatizando la participación del pintor no solo en la realización de obras públicas, sino también en la búsqueda de una germinal institucionalización de la esfera artística. Por último, Pagano (1945) solidificó su tesis en torno a la importancia del artista en el decurso del arte nacional, en una voluminosa obra que por tratarse de una producción financiada por el MNBA le asignó una especial relevancia al estudio catalográfico. Merece atención allí el "Índice descriptivo» (1945) realizado por Alfredo González Garaño, el cual resultó una hasta entonces inédita y exhaustiva catalogación de la obra de Pueyrredón. ${ }^{3}$ Expuesto de manera simplificada, podemos señalar que mientras Brest hizo hincapié en el estilo, D'Onofrio lo hizo en el contexto y Pagano en las implicancias de su pintura en la conformación del espíritu nacional. El sendero hermenéutico sobre Pueyrredón parecía así bifurcarse en múltiples direcciones.

Durante el gran período comprendido entre las décadas de 1950 y 1990 los trabajos citados continuaron siendo referencia por no efectuarse estudios que abordaran exhaustivamente la obra de Pueyrredón. Destacan no obstante dos publicaciones que dieron cuenta del recorrido del artista, aunque de modo acotado por tratarse de estudios generalistas. Nos referimos a Monumenta Iconographica, de Bonifacio del Carril, en 1964 y al emprendimiento impulsado por la editorial Viscontea en 1966. El primero resultó un ambicioso estudio iconográfico sobre el arte de los argentinos desde 1536 hasta 1860 lanzado en conmemoración del sesquicentenario de la Revolución de Mayo, el cual implicó más que una mera recopilación de obras, ya que se trataba de un compendio de iconografías sobre los usos y las costumbres

2 La Escuela dependió en sus orígenes de la Sociedad Estímulo de Bellas Artes hasta 1905, cuando se trasladó la potestad de la enseñanza artística municipal a la Academia Nacional de Bellas Artes (ANBA). Desde 1927 el colegio funcionó bajo el nombre de Escuela de Artes Decorativas de la Nación, hasta 1940.

3 Esta elaboración catalográfica es la más exhaustiva y detallada hasta nuestros días. Vale mencionar que en la actualidad el sitio web del MNBA posee un logrado recorrido visual y puesta en valor de la obra de Pueyrredón. Como es de esperarse, solo se trata de las pinturas que están dentro de su patrimonio (46 en total, entre acuarelas, óleos y dibujos), las cuales además de ofrecer reproducciones en alta definición se encuentran acompañadas de referencias analíticas y estudios a cargo de Roberto Amigo, principal especialista en la actualidad en la vida y obra de Pueyrredón (González Garaño, 1944). 
de nuestro país en su etapa de gestación de la nacionalidad. Entre sus páginas se incluyó a Pueyrredón como un pintor "costumbrista» que retrató «la vida culta y civilizada del Buenos Aires de antaño" (Del Carril, 1964, p. 72). Por su parte, el proyecto impulsado por Viscontea sobre Arte argentino contó con el apoyo de la Comisión Nacional para la Unesco. Pueyrredón ocupaba un espacio destacado en sus primeros fascículos con textos de Romero Brest y de Samuel Oliver. El primero volvió a ubicarlo como el precursor de los artistas argentinos mientras el segundo lo calificó como el retratista de la elite del siglo XIX, otorgándole en ambos casos un lugar medular en la constelación artística decimonónica local. Además de estos dos proyectos existen menciones en otras publicaciones. Manuel Mujica Láinez realizó un relato ficcional en su cuento "El pintor de San Isidro" dentro de Aquí vivieron (1962), mientras que trabajos de otra naturaleza también darían cuenta del recorrido del pintor y su obra como los diccionarios de Ricardo Piccirilli (1954), Vicente Cutolo (1968) o las enciclopedias de Romualdo Brughetti (1965) y Vicente Gesualdo (1968).

Ya en la década de 1970 Julio Payró inscribió a Pueyrredón como uno de los pintores de la Argentina, dedicando un libro a él y a Joseph Dubordieu con motivo de sus reformas en la Plaza de la Victoria (Payró, 1970; Payró, 1972). En noviembre de 1970 durante el centenario del fallecimiento del artista, el Museo Pueyrredón efectuó una muestra retrospectiva de sus pinturas con un estudio preliminar de Marcos de Estrada (1970), director de la entidad. Las referencias a partir de entonces comienzan a multiplicarse, y se reivindica el eclecticismo y la versatilidad del artista, poniendo de relieve su polifacética producción como arquitecto, ingeniero y paisajista (Aguilera, 1971); inscribiéndolo como el retratista por excelencia del siglo XIX (Ribera, 1982); posicionándolo como un "pintor criollista" que "reaccionó" ante la europeización (Romero, 2004) o considerándolo un protagonista en el devenir de San Isidro (Lozier Almazán, 1986).

Estas indagaciones constituyen un acervo bibliográfico extenso al cual hemos denominado abordajes clásicos en virtud de la perspectiva heurística que en general adoptan. Exceptuando el trabajo pionero de D'Onofrio y su mirada complejizada sobre el artista, en mayor o menor medida los trabajos citados colocaron al personaje en el centro de la escena y a sus obras como productos de un genio o voluntad creadora. Ahora bien, en parte gracias al eclecticismo de Pueyrredón y junto con una renovación historiográfica en el terreno de la historia del arte local, en los últimos años se ha revisitado su figura con nuevos impulsos.

\section{NUEVOS ENFOQUES}

El panorama historiográfico aquí referido se vio severamente modificado a partir de la década de 1990. Influenciados por una tendencia revitalizante de los estudios visuales a nivel global y por el (re)posicionamiento de la imagen dentro de las ciencias sociales, la historiografía del arte argentino experimentó una renovación vinculada a las figuras de Adolfo Luis Ribera, Hector Schenone y José Emilio Burucúa. Este último será de gran incidencia por ser quien "modifica la manera de "hacer" historia del arte» (Siracusano, 2010, p. 68), otorgando gran peso a la relación entre imágenes e ideas. Producto de estas derivaciones e innovaciones historiográficas se reavivó el interés por autores que, como Pueyrredón, ofrecían posibilidades metodológicas novedosas dada la multiplicidad de registros que cultivaron.

Así, en 1995, surgió un trabajo clave como el breve pero consistente examen de Laura Malosetti Costa en donde revisitaba una faceta hasta entonces poco explorada: la del pintor de desnudos sugerentes y eróticos en el Buenos Aires de mediados de siglo XIX. Se propuso desmitificar la figura de Pueyrredón como un artista enigmático que con sus desnudos intentaba crear cuadros obscenos y lascivos, destinados al consumo personal y no para ser expuestos en público. Para indagar en ello, Malosetti Costa (1995) recurrió a fuentes periódicas como El Nacional y La Tribuna que le permitieron postular que El baño y La siesta (ambos de 1865) representaban un punto de tensión entre lo público y lo privado. Planteó, además, la hipótesis de trabajo de que dichas obras constituían parte de un entramado mayor como 
el afrancesamiento de la clase alta porteña, lo que reforzó su postulado inicial respecto a la finalidad de consumo privado de estas producciones, guardando las modas francesas para la intimidad. Propuso, finalmente, que estos registros no fueron producto del "capricho" de un "excéntrico" pintor, sino "una primera entrada de la tradición europea del desnudo erótico» (Malosetti Costa, 1995, p. 133). Teniendo en cuenta la experiencia formativa parisina de Pueyrredón, así como la hegemonía cultural francesa en el espacio local y la reconfiguración de la sociedad porteña durante aquellos años, las conclusiones de Malosetti Costa representan una interpretación compleja, articulada y estimulante de tales obras.

En 1999 el Banco Velox editó un trabajo con la colaboración de Roberto Amigo, Patricia Giunta y Félix Luna. El primero fue quien inscribió la obra de Pueyrredón como un dispositivo central para comprender un fenómeno más amplio como la cultura visual porteña de mediados del siglo XIX. Desde su óptica estas pinturas respondieron a nuevos patrones artístico-culturales que, aun estando sujetos a las condiciones de producción local, posibilitaron una ampliación y expansión de la visualidad burguesa. Retomando los postulados expuestos por Pilar González Bernaldo de Quirós (1999) en su tesis doctoral sobre las formas de construcción de una identidad colectiva-nacional, Amigo destacó la participación del artista en diferentes ámbitos de sociabilidad como los sitios de difusión de la visualidad (Luna y otros, 1999). Evaluó en este sentido que el artista contribuyó a la creación de formas simbólicas de identidad común ancladas en la pertenencia a una elite porteña, lo cual «determinó las figuras que ocuparon el lugar de la memoria nacional» (Luna y otros, 1999, p. 31). Siguiendo esta línea, Giunta hizo hincapié en la importancia del artista en su época y en el peso que tuvo en la construcción de un arte nacional junto a otros pintores como Carlos Morel y Cándido López. Según Giunta (en Luna y otros, 1999) lo que distinguió a Pueyrredón fue la definición del «espacio de la pampa como ningún otro artista lo hizo antes, transmitiendo la esencia de ese desierto, de esas grandes extensiones de planicie» (p. 74).

Aquel mismo año, dentro de la colección Nueva Historia Argentina editada por Sudamericana bajo la dirección de José Emilio Burucúa, María Lía Munilla Lacasa (1999) destacó la multiplicidad de labores en las que se desempeñó Pueyrredón, resaltando las cualidades plásticas del artista y señalando que con sus pinturas campestres «describió las características geográficas y sociales de la pampa argentina" (p. 145). Algunos años después Marta Penhos (2008) empleó Un alto en el campo (1861) para ubicarla como parte de una construcción paisajística que contaba una dilatada tradición compuesta además por relatos de viajeros e iconografías. También Aimé Iglesias y Andrea Peresan (2008) revisitaron las obras como el desnudo El Baño (1865) desde una perspectiva diferente a la de Malosetti Costa, analizando el papel social que desempeñaba la mujer en la cultura porteña. Si bien postularon que la pieza fue concebida como experiencia pictórica privada destacaron que el artista se apartó de los cánones objetualizantes de la mujer para construir un retrato más íntimo y personal del modelo femenino.

Similar camino transitaron indagaciones más recientes que revitalizaron la importancia del artista en vínculo con el contexto (Gutiérrez Zaldívar, 2009; Alemán, 2011; Giurliani, 2012), el mercado de la época y las expresiones republicanas (Amigo, 2014) o bien examinaron sus pinturas de carácter rural como expresiones simbólicas de una vanguardia terrateniente (Masán, 2017). Cada una de estas indagaciones, aunque diferentes entre sí, nos ofrecen distintas puertas de entrada al fenómeno pictórico y nos muestran la actualidad de su figura, un siglo y medio después de su nacimiento.

\section{REFLEXIONES FINALES}

Tras este recorrido se advierte en la metodología de numerosos trabajos la predominancia de una perspectiva anclada en las características subjetivas del artista como vehículo heurístico para explicar sus obras. De allí que se hayan concebido a sus pinturas como una síntesis de la 
imaginería de un artista excelso, con extraordinario manejo de la técnica y/o que decide dejar su testimonio para las generaciones futuras.

Al margen de estos posibles anacronismos y entendiendo que el campo de la historia del arte busca atender a la subjetividad reparando también en el contexto social y visual, consideramos que existen ejemplos que complejizan los postulados clásicos. En este sendero transitan el temprano y pionero examen de D'Onofrio o las más recientes indagaciones de Malosetti Costa, Amigo, Penhos o Iglesias y Peresan. Tales miradas han considerado a las producciones como una creación inscripta en un entramado de mayor complejidad que las dota de sentido, sea un imaginario nacional, una visión republicana, normas de sociabilidad propias del mundo de la elite o bien una cultura visual burguesa en expansión.

Las riquezas, las matizaciones y los aportes de esta literatura durante casi un siglo de producción sobre Pueyrredón evidencian una variedad de enfoques que esta figura nodal del arte decimonónico permite. La complejidad del personaje, entonces, también nos invita a escrutar, tanto lo efímero del copo de nieve como la abrumadora avalancha (Jablonka, 2015). Frente a sus pinturas y a través suyo.

\section{REFERENCIAS}

Aguilera, N. (1971). Prilidiano Pueyrredón, arquitecto, urbanista, ingeniero. Cuadernos de Historia del Arte, (10), 69-86.

Alemán, J. (2011). Prilidiano Pueyrredón. Ciudad Autónoma de Buenos Aires, Argentina: Arte Gráfico Editorial Argentino.

Amigo, R. (2014). Pintura Republicana: Colección del Museo Pueyrredón. San Isidro, Argentina: Municipalidad de San Isidro.

Brughetti, R. (1965). Historia del arte en argentina. Ciudad de México, México: Pomarca.

Cabra, G., García Martín, C. y Rivas, M. (2017). El retrato de Manuelita Rosas. Entre el valor histórico y el estético. Nimio, (4), 57-66. Recuperado de http://papelcosido.fba.unlp.edu.ar/ ojs/index.php/nimio/article/view/544

Casas, M. E. (2013). Gauchos y católicos: el origen de las peregrinaciones gauchas a la basílica de Luján, Buenos Aires, 1945. Anuario de la Escuela de Historia, (25), 257-275. Recuperado de http://hdl.handle.net/11336/28987

Casas, M. E. (2016). Entre peronistas y radicales: disputas en torno al monumento al gaucho en la provincia de Buenos Aires, 1947-1948. Prohistoria, 19(25), 53-78. Recuperado de http://hdl.handle.net/11336/46393

Cataruzza, A. (2009). Historia Argentina, 1916-1955. Ciudad Autónoma de Buenos Aires, Argentina: Siglo Veintiuno.

Cataruzza, A. (Dir.). (1999). Nueva Historia argentina. Tomo 7: Crisis económica, avance del Estado e incertidumbre política (1930-1943). Ciudad Autónoma de Buenos Aires, Argentina: Sudamericana.

Cutolo, V. (1968). Nuevo Diccionario biográfico argentino (1750-1930). Tomo 5: N-Q. Ciudad Autónoma de Buenos Aires, Argentina: Elche.

D’Onofrio, A. (1944). La época y el arte de Prilidiano Pueyrredón. Ciudad Autónoma de Buenos Aires, Argentina: Sudamericana.

De Estrada, M. (1970). Prilidiano Pueyrredón. Exposición de obras del artista, en el centenario de su fallecimiento. San Isidro, Argentina: Fondo Nacional de las Artes.

Del Carril, B. (1964). Monumenta Iconographica. Paisajes, ciudades, tipos, usos y costumbres de la Argentina, 1536-1860. Ciudad Autónoma de Buenos Aires, Argentina: Emecé.

Gesualdo, V. (1968). Enciclopedia del Arte en América. Tomo 4. Ciudad Autónoma de Buenos Aires, Argentina: Omega.

Giurliani, G. (2012). La Colección Prilidiano Pueyrredón del Museo Pueyrredón. En Investigación Curatorial para el Espacio de Arte Prilidiano Pueyrredón de la Asociación Amigos del Museo Pueyrredón. San Isidro, Argentina: Academia Argentina de Cultura. Recuperado de http://amgosdelmuseopueyrredon-espaciodearte.blogspot.com.ar/ 
Gutiérrez, R. (7 de octubre de 1933). La obra de Pueyrredón en Amigos del Arte. Caras y Caretas, 125-126.

Gutiérrez Zaldívar, I. (2009). El arte de los argentinos. Prilidiano Pueyrredón. Ciudad Autónoma de Buenos Aires, Argentina: Atlántida.

Iglesias, A. y Peresan, A. (2008). Desnudo subjetivo, aproximaciones contextuales y plásticas a la obra El baño de Prilidiano Pueyrredón. AdVersus, 5(12-13), 133-151. Recuperado de https://dialnet.unirioja.es/servlet/articulo?codigo=2913201

Jablonka, I. (2015). Historia de los abuelos que no tuve. Ciudad Autónoma de Buenos Aires, Argentina: Libros del Zorzal.

Lozier Almazán, B. (1986). Reseña histórica del Partido de San Isidro. San Isidro, Argentina: Las Lomas.

Luna, F., Amigo, R. y Giunta, P. (1999). Prilidiano Pueyrredón. Ciudad Autónoma de Buenos Aires, Argentina: Banco Velox.

Malosetti Costa, L. (1995). Los desnudos de Prilidiano Pueyrredón como punto de tensión entre lo público y lo privado. Ponencia presentada en las 6. Jornadas de Teoría e Historia de las Artes. Centro Argentino de Investigadores de Arte, Ciudad Autónoma de Buenos Aires, Argentina.

Masán, L. (2017). Escenas del mundo rural de Prilidiano Pueyrredón. Un modo de ordenamiento de la campaña en Buenos Aires, 1860-1867 (Tesis de maestría). Universidad Nacional de Quilmes, Quilmes, Argentina.

Mujica Láinez, M. (1962). El pintor de San Isidro. En Aquí vivieron. Historias de una quinta de San Isidro, 1583-1924 (pp. 74-77). Ciudad Autónoma de Buenos Aires, Argentina: Sudamericana.

Munilla Lacasa, M. (1999). Siglo XIX: 1810-1870. En J. E. Burucúa (Dir.), Nueva Historia Argentina. Arte, sociedad y política. Tomo I. Ciudad Autónoma de Buenos Aires, Argentina: Sudamericana.

Navarro, M. A. (2016). 120 años de Bellas Artes. Obras fundacionales del Museo Nacional de Bellas Artes. Ciudad Autónoma de Buenos Aires, Argentina: Asociación Amigos del Museo Nacional de Bellas Artes.

Oliver, S. (1966). Argentina en el arte: El retrato en el siglo XIX. Ciudad Autónoma de Buenos Aires, Argentina: Viscontea.

Pagano, J. (6 de noviembre de 1932). Prilidiano Pueyrredón. La Nación.

Pagano, J. (1937). El arte de los argentinos. Ciudad Autónoma de Buenos Aires, Argentina: Edición del Autor.

Pagano, J. (1945). Prilidiano Pueyrredón. Ciudad Autónoma de Buenos Aires, Argentina: Academia Nacional de las Artes.

Payró, J. (1970). 23 pintores de la Argentina (1810-1900). Ciudad Autónoma de Buenos Aires, Argentina: EUDEBA.

Payró, J. (1972). Prilidiano Pueyrredón, Joseph Dubordieu, la pirámide de mayo y la Catedral de Buenos Aires. Ciudad Autónoma de Buenos Aires, Argentina: Universidad de Buenos Aires.

Penhos, M. (2008). Modelos globales frente a espacios locales: tensiones en la obra de dos artistas europeos en la Argentina del siglo XIX. Studi Latinoamericani, (4), 1-10.

Piccirilli, R. (Dir.). (1954). Diccionario Histórico Argentino. Ciudad Autónoma de Buenos Aires, Argentina: Artes gráficas.

Ribera, A. (1982). El retrato en Buenos Aires, 1580-1870. Ciudad Autónoma de Buenos Aires, Argentina: Universidad de Buenos Aires.

Romero Brest, J. (1942). Prilidiano Pueyrredón. Monografías de arte americano. Ciudad Autónoma de Buenos Aires, Argentina: Losada.

Romero Brest, J. (1966). Argentina en el arte: Prilidiano Pueyrredón. Ciudad Autónoma de Buenos Aires, Argentina: Viscontea.

Romero, J. L. (2004). La experiencia argentina y otros ensayos. Ciudad Autónoma de Buenos Aires, Argentina: Taurus.

Schiaffino, E. (1933). La pintura y la escultura en Argentina (1793-1894). Ciudad Autónoma de Buenos Aires, Argentina: Edición del Autor. 
Siracusano, G. (2010). Historiografía del arte argentino. Expeditio, (2), 63-73. Recuperado de https://revistas.utadeo.edu.co/index.php/EXP/article/view/698 